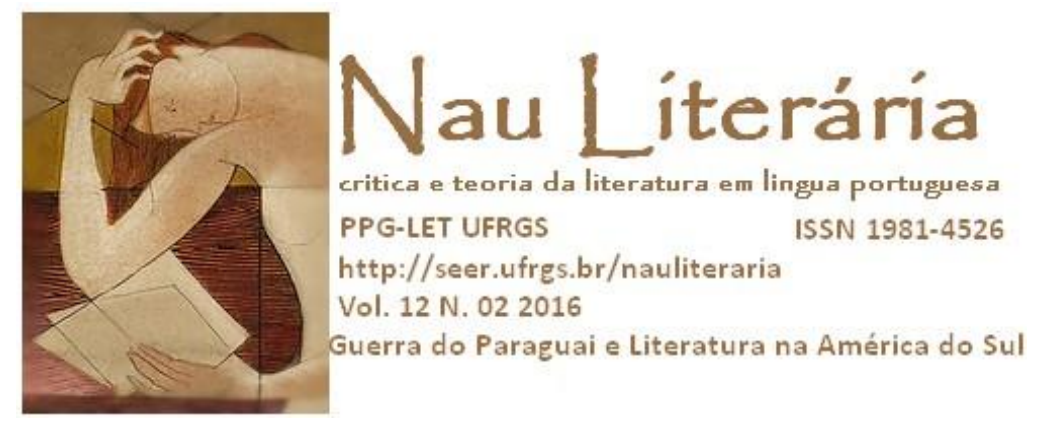

\title{
A Guerra do Paraguai na imprensa e na literatura de língua alemã publicada no Brasil
}

\author{
Gerson Roberto Neumann \\ UFRGS
}

Resumo: A Guerra do Paraguai foi um marco histórico no Brasil. Não queremos discutir aqui aspectos negativos ou positivos da guerra, mas observar como ela repercutiu na imprensa em língua alemã publicada no Brasil. Muitos imigrantes e filhos de imigrantes alemães lutaram nessa guerra e muitas foram as críticas aos líderes políticos por forçarem os imigrantes a participar da guerra. Muitos morreram na guerra, outros sobreviveram. Alguns registraram sua participação na guerra em forma de texto, publicados na imprensa em língua alemã.

Palavras-chave: Guerra do Paraguai; literaratura, imigração alemã.

\begin{abstract}
The Paraguayan War marked a historic milestone in Brazil. We do not want to discuss here the negative or positive aspects of the war, but to observe its repercussions in the German language press published in Brazil. Many immigrants and children of German immigrants fought in this war and there has been a great deal of criticism of political leaders for forcing immigrants to take part in it. Many died in the war, others survived. Some registered their participation in the war in text form, published in the German language press.
\end{abstract}

Keywords: Paraguayan War; Literature, German immigration.

\section{Introdução}

O tema que aqui se propõe apresentar é resultado de algumas apresentações em simpósios, colóquios e congressos. A Guerra do Paraguai é um tema pouco recorrente na literatura brasileira e menos ainda se a publicação for em língua alemã no Brasil. A Guerra do Paraguai como tema na produção e crítica literária parece ter sido esquecida nas gavetas 
da história. No caso proposto aqui, parece que foi esquecida nos arquivos, pois o que se propõe, e este é o objeto da pesquisa, é apresentar um poema em língua alemã publicado no Brasil sobre a Guerra do Paraguai por um combatente de origem alemã.

Chegou-se a este tema através de pesquisas de campo realizadas para o Projeto ALMA-H (Atlas Linguístico-Contatual das Minorias Alemãs da Bacia do Prata), coordenado pelo Prof. Dr. Cléo V. Altenhofen, da UFRGS (Porto Alegre - Brasil) e pelo Prof. Dr. Harald Thun, da Universität Kiel (Kiel - Alemanha). Nas muitas conversas com falantes da variante dialetal alemã Hunsrückisch no Brasil, muitas delas de mais de quatro horas, constantemente tocava-se no tema da guerra, muito presente no contexto de imigração alemã no Brasil, do século XIX até a eclosão da Segunda Guerra Mundial. ${ }^{1}$ Interessante foi localizar em pesquisas bibliográficas um poema e uma série de artigos sobre a participação de imigrantes alemães e seus descendentes na Guerra do Paraguai. A partir da localização de um poema de Nicolau Engelmann, no almanaque Kalender für die Deutschen in Brasilien e da localização de um poema bastante semelhante por parte de Altenhofen, começou-se a trabalhar mais ativamente no que se apresenta aqui neste momento.

Trata-se, portanto, de um poema de Nicolau Engelmann e um de Jakob Dilly ambos do contexto de imigração alemã, combatentes na Guerra do Paraguai. Pretende-se apresentar também outras referências, publicadas em três diferentes almanaques (Kalender) publicados em língua alemã até a Segunda Guerra Mundial, que possam complementar o tema da Guerra do Paraguai na literatura. Contudo, antes de apresentarmos e analisarmos mais detalhadamente o poema de Nicolau Engelmann, publicado, portanto, no Kalender für die Deutschen in Brasilien, é importante localizar a imigração alemã no contexto brasileiro e observar como se desenvolveu a imprensa em língua alemã no Brasil, onde os autores viriam a publicar os seus textos. A produção de tal literatura está claramente associada ao contexto sócio-histórico da imigração alemã no Brasil, no século XIX. No terceiro momento, será realizada a análise do texto em questão.

\section{A imigração alemã no Brasil}

\footnotetext{
1 Acompanharam o contexto de imigração alemã no Rio Grande do Sul as seguintes guerras e revoluções: Revolução Farroupilha (1835 - 1845), Guerra do Paraguai (1864 - 1870) e Revolução Federalista (1893 1895).
} 
A imigração alemã para o Brasil inicia em 1824, mantendo regularidade e com apoio aos imigrantes por parte do Governo Imperial. Por motivos políticos, os imigrantes não poderiam ser espanhóis, o que se explica pelo fato de as fronteiras do Brasil serem em grande parte com países de língua espanhola; holandeses e franceses já haviam invadido terras brasileiras anteriormente no Nordeste e Sudeste e, além disso, tinham colônias na América do Sul; nem ingleses, pelo estreito contato político da Inglaterra com os portugueses. Cabe lembrar que a independência política do Brasil se deu em 1822; dois anos mais tarde, portanto, iniciaria a imigração de alemães. Desta forma, o panorama político era favorável à imigração de alemães. Outro fator que favoreceu a emigração de alemães para Brasil foi o casamento de Dom Pedro com a princesa austríaca Leopoldine, da casa de Habsburgo. A própria princesa foi acompanhada por uma comitiva científica ao chegar ao Brasil. Entre os cientistas que permaneceriam por longo tempo no Brasil estavam Carl Friedrich Philipp von Martius (1794-1868) e Johann Baptist von Spix (1781-1826), entre outros.

Em meio a esse contexto, chegam os primeiros imigrantes alemães ao Brasil. Entre os registros deixados por estes primeiros alemães podem ser citados relatos e, principalmente, cartas. A primeira geração de imigrantes alemães no Brasil não teve possibilidades de produção literária de ficção. Não se tem registro de produção literária de 1824 a 1850. A partir de 1850 chegam mais e mais famílias de outras camadas sociais ao Brasil, muitas vezes famílias que não deixavam a sua terra por questões econômicas, como fora até então. Muitos destes imigrantes deixam a sua terra também por motivos políticos. Em números, trata-se de um grupo menor em comparação aos que deixam a sua terra por pobreza e motivados por uma possibilidade de vida melhor no Brasil: são os perseguidos políticos. Apesar de ser um grupo menor, estes serão os responsáveis por uma agitação política e cultural no cenário imigratório alemão no Brasil, caracterizado pelo trabalho braçal principalmene no meio rural. Muitos desses imigrantes participaram da Revolução de 1848, na qual buscavam uma unidade nacional alemã. Com a frustração dos ideais revolucionários, tiveram como única possibilidade a emigração. Muitos desses revolucionários emigram como mercenários ou soldados para os Estados Unidos, outros 
tantos dirigem-se para a América do Sul, também como mercenários, e são engajados pelo Governo brasileiro na Guerra de La Plata contra o ditador argentino Rosas. ${ }^{2}$

Esses mercenários tornaram-se figuras emblemáticas no contexto de imigração alemã no Brasil, passando a ser conhecidos como Brummer, um conceito que se estabelece na história da imigração alemã no Brasil. Segundo Kreutz (1991), a definição Brummer quer dizer, por um lado, "aquele que causa alvoroço, agitação"3; eles são resmungões, pois questionam tudo que lhes é oferecido. Por outro lado, os mercenários são chamados Brummer pelo fato de trabalharem pelo dinheiro, pelo Patacão ${ }^{4}$ que zune quando lançado sobre a mesa. A história da imigração alemã no Brasil não será aprofundada aqui por não ser o objetivo principal neste momento. Além disso, já existem muitas pesquisas e publicações relevantes que o fazem e podem ser consultadas. ${ }^{5}$

Os primeiros imigrantes alemães já viviam há 40 anos no Brasil quando se inicia a guerra entre Brasil e Paraguai, em 1864. A guerra também é conhecida como a Guerra da Tríplice Aliança, e se estende até 1870. De um lado está o Paraguai e de outro a aliança entre Argentina, Brasil e Uruguai. Ao final, o cenário será de destruição total do Paraguai e a guerra será considerada a mais sangrenta na história latino-americana. Muitos imigrantes alemães foram recrutados para esta guerra pelo Governo brasileiro e muitos perderam suas vidas. O livro Alemães e descendentes do Rio Grande do Sul na Guerra do Paraguai, de Klaus Becker (1968), descreve a participação de imigrantes e traz muitas informações sobre este acontecimento.

\section{A literatura em língua alemã no Brasil}

Nesse cenário, foi fundado o primeiro jornal para as comunidades alemãs no Brasil, em 1852: Der Kolonist. Seu editor foi o diretor do diário O Mercantil, José Gomes Cândido, curiosamente um empreendedor de origem não germânica. Esse primeiro jornal, no entanto, teve uma breve existência. Os temas por ele abordados giravam em torno do

\footnotetext{
${ }^{2}$ Sobre o tema, ver Cem anos de germanidade no Rio Grande do Sul. Trad. Arthur B. Rambo. São Leopoldo: UNISINOS, 1999, p. 151-154.

${ }^{3}$ KREUTZ, L. 1991, p. 22.

4 Trata-se de uma moeda do Império brasileiro.

5 Sobre a história da história da imigração alemã no Brasil, ver BADE, 1980; HUNSCHE, 1975; KREUTZ, 1991; MÖNCKMEIER, 1912; ROCHE, 1969, entre outros.
} 
comércio, da indústria e da agricultura e também se traduziam as principais leis do Império. O objetivo do jornal era ampliar o tão relevante conhecimento geral dos colonos para uso no dia-a-dia brasileiro. ${ }^{6}$

O segundo jornal - Der deutsche Einwanderer - foi fundado no Rio de Janeiro. Por dificuldades financeiras, o seu fundador, Dr. Kiekbach, transferiu a sede do jornal para Porto Alegre no ano de 1854, sendo comprado mais tarde por Theobald Jaeger. Seu primeiro redator-chefe foi Carl Jansen, um Brummer. Esse jornal também não teve longa existência, parando suas atividades em 1861. Ainda assim, no mesmo ano, a estrutura do jornal foi adquirida por um grupo de comerciantes e entre eles estavam integrantes da antiga legião de soldados alemães, Brummer. Dessa iniciativa surgiu o primeiro jornal em língua alemã que desenvolveu um longo e importante trabalho no Brasil, existindo até 1917: Deutsche Zeitung. Importantes redatores passaram pelo jornal, entre eles Karl von Koseritz, uma das mais importantes figuras no contexto jornalístico-cultural da fase inicial da imprensa em língua alemã no Brasil. O Deutsche Zeitung caracterizava-se por sua orientação liberal e anticlerical.

Depois dessa primeira experiência exitosa, a atividade jornalística teuto-brasileira intensificou-se; outros jornais surgiram, também fora da capital do Rio Grande do Sul. Em São Leopoldo, então o local com a maior concentração de imigrantes, Julius Curtius fundou, no ano de 1867, o almanaque Der Bote. Amtliches Blatt für St. Leopold und die Colonien. Esse jornal era igualmente de tendência anticlerical, mas, devido a divergências políticas relativas à colonização alemã no Brasil, tomou um posicionamento de oposição em relação ao Deutsche Zeitung. No entanto, em São Leopoldo será fundada uma editora que dará uma importante contribuição ao contexto literário da imigração alemã. No ano de 1874 chega ao Brasil o pastor luterano Wilhelm Rotermund, que compra uma editora que mais tarde será conhecida como Editora Rotermund e por longo tempo será uma das mais importantes referências para publicações de literatura no contexto de imigração alemã no Brasil. Entre suas publicações mais relevantes está o almanaque Kalender für die Deutschen in Brasilien, que mais tarde será conhecido como Rotermundkalender.

É importante ressaltar que o cenário político-cultural da imigração alemã no Brasil não era de uma convivência harmoniosa, principalmente depois da chegada dos Brummer.

${ }^{6}$ Ver FAUSEL, 1956, p. 225. 
Visto que este grupo era formado basicamente por liberais e por isso se opunha ao tradicionalismo religioso (tanto ao católico como também ao protestante-luterano), estabeleceu-se um movimento anti-Brummer, que agitou o cenário editorial. Desta forma, a Igreja Católica e a protestante-luterana tornaram-se oposição aos ideais liberais. O ganhador nesta briga foi o contexto cultural da imigração alemã no Brasil, pois o conflito gerou diversas publicações que pretendiam atingir o leitor e com isso ganhar terreno no que se refere a leitores fiéis, assim como no campo ideológico.

No editorial do suplemento literário Unterm Südlichen Kreuz, do jornal Deutsche Post, foi publicado, no ano de 1899, uma importante reflexão sobre a publicação de textos literários em língua alemã "sob um outro céu”, em um outro "contexto". Enfatizou-se, acima de tudo, o fato de que esta produção também devia ser acessível para aquele que quisesse ler. Segundo o autor Wilhelm Rotermund, produção já existia, mas até então havia poucas possibilidades de publicação, como se pode ler abaixo:

Passamos aqui pela encantadora natureza e por fim, nós mesmos ficamos encantados. Tivéssemos nós alguém que abrisse os nossos olhos para as inúmeras belezas e nô-las esclarecesse! Não é correto que se nos guiem sempre sob a Ursa Maior do céu do Norte, quando habitamos sob o Cruzeiro do Sul, e festejemos Natal em neve e gelo, quando mal sabemos conviver com o calor (...). Seria bom e certamente também útil se tivéssemos uma série de retratos sérios e alegres das pessoas e da terra, sob a qual o Cruzeiro do Sul faz a sua trajetória silenciosa. Muitos, isto eu sei, já fizeram tal estudo, mas deixaram-no descansar na pasta, porque, segundo eles, não havia emprego para este tipo de esboço. ${ }^{7}$

Quando se trata da literatura de imigração alemã no Brasil, é preciso ter em mente que se trata de uma literatura de claro fundamento sócio-histórico. Especialmente em relação à imigração alemã, sempre é necessário lançar um olhar para o século XIX.

\section{A Guerra do Paraguai como tema na imprensa em poesia e prosa}

A seguir pretende-se apresentar textos em que a Guerra do Paraguai passa a ser tema na imprensa de língua alemã publicada no Brasil.

\footnotetext{
7 "Wir gehen hier durch die zauberhafte Natur zuletzt selber verzaubert hindurch. Hätten wir doch nur jemanden, der unsere Augen öffnete für die vielen Schönheiten und sie uns erklärte! Es ist doch nicht recht, da $\beta$ man uns immer dem Grossen Bären des nordischen Himmels führt, wo wir unter dem südlichen Kreuz wohnen (...). Schön wär's schon und auch gewiß nützlich, wenn man in einer Reihe ernster und heiterer Bilder das Land, über welchem das Kreuz des Südens seine stillen Kreise zieht, und auch die Menschen darin abkonterfeien würde. Mancher, das weiß ich, hat schon solche Zeichenstudien gemacht, aber sie in der Mappe ruhen lassen, weil er für derartige Skizzen keine Verwendung hatte Unterm südlichen Kreuz." O texto foi publicado em 4 de janeiro de 1899. Tradução livre nossa.
} 
No livro Alemães e descendentes do Rio Grande do Sul na Guerra do Paraguai, de Klaus Becker, já mencionado acima, podem ser lidos os diários de cinco participantes da guerra: do capitão Pedro Werlang, do capitão Jacob Franzen, do terceiro-sargento Jacob Dick, do sargento Christiano Spindler, assim como do sargento Nicolau Engelmann. A forma usada pelos veteranos de guerra para a sua produção dos relatos (literários) de guerra no intuito de chamar a atenção do leitor atento dá-se em prosa e se mantém bastante fiel aos relatos históricos. O poema, por sua vez, quanto ao conteúdo, também se mantém fiel aos relatos históricos.

Nos textos em prosa podem se perceber diferentes formas usadas: em um é usada uma forma de relato progressivo baseado em fatos históricos. O leitor acompanha o soldado no seu dia a dia na guerra. Em outro, são descritos os fatos mais importantes; em um terceiro, lê-se as vivências mais importantes do autor assim como as aventuras e as experiências mais chocantes em solo paraguaio. Merece destaque no poema o fato de ser um poema longo, uma epopeia, com rimas finais. O poema é escrito na forma de Knittelvers. ${ }^{8}$

Passamos, a seguir, à apresentação do poema e dos textos em prosa.

\subsection{O poema de Nicolau Engelmann}

O próprio Nicolau Engelmann passa ao leitor informações sobre sua origem na introdução de seu poema. No Kalender für die Deutschen in Brasilien lê-se o seguinte:

Nasci no dia 1 de novembro de 1845 na localidade do Baumschneiß (hoje Dois Irmãos), filho de Heinrich Engelmann e sua esposa Catharina, nascida Cloß. Ainda não tinha completado meus 17 anos, quando eu já andava em São Leopoldo com sabre na cintura, mas

\footnotetext{
${ }^{8}$ A origem do Knittelvers está, aparentemente, em países de língua alemã. Trata-se de um verso alemão praticado desde o século XV até o início do século XVII, usado em todas as formas líricas não cantadas, portanto, na poesia, na épica e no drama, e em tradução livre significa "verso rimado" (Reimvers). A origem do conceito também pode estar no termo knüttel, mas no sentido de entremeado, de versos não tão bons e irregulares. No verso há quatro acentos e as rimas estão em pares. No que se refere à forma, é importante para um Knittevers que existam rimas (a-a, b-b, c-c), as chamdas rimas pares. Há dois tipos de formas principais: o Knittelvers rígido, que na sua cadência é composto de 8 ou 9 sílabas por verso; e o Knittelvers livre, que pode variar no número de sílabas. Hans Sachs (1494-1576) foi certamente um dos mais conhecidos representantes da forma rígida. Aqui um exemplo em "Wittenbergisch Nachtigall" (1523): "Wacht áuff es náhent gén dem tág/ Jch hóer singén im grúinen hág" (ROTHMANN, 1992, p. 36. Os acentos foram marcados). Além de Hans Sachs pode-se destacar outros importantes representantes dessa forma, como, por exemplo, Hans Rosenplüt (1400-1460 o poeta do Carnaval), e Sebastian Brant (1457-1521) com Das Narrenschiff (1494), assim como Johann Fischart (1546-1590).
} 
não para mim, e sim para meus irmãos que já estavam na Guarda Nacional. A primeira vez prestei serviço pelo meu irmão Jacob, que mais tarde cairia na Guerra do Paraguai, onde encontrou seu descanso eterno. (ENGELMANN, 1921, p. 193) $)^{9}$

Nicolau Engelmann convoca seus campanheiros de guerra a também relatarem sobre suas impressões e experiências na Guerra do Paraguai para que a contribuição da “Bateria Alemã” seja lembrada. A seguir, as palavras de Nicolau Engelmann (Fig. 1):

Estimados camaradas!

Todos nós lutamos pela honra da nossa pátria. A todos vocês que ainda estão em vida chegue hoje a minha saudação. Muitos de nós já deram baixa do grande exército nesses 42 anos. Aqui e ali li necrológios no "Deutsche Post". Assim também chegará a nossa vez. Aí não seja esquecido que a Bateria Alemã teve uma contribuição importante na vitória na Guerra do Paraguai. Por isso sempre se dizia: "Viva a Bateria dos Alemães!" Por isso, caros camaradas, saudações! (ENGELMANN, 1921, p. 201)

O poema apresenta muitos elementos para análise, dos quais neste momento, contudo, poderão ser observados apenas alguns. Será feita uma seleção de pontos para apresentar nesta análise. Engelmann inicia imediatamente com informações biográficas, dizendo que "entrou no seu vigésimo ano de vida". Seu poema inicia de forma não rígida, contudo os 276 versos apresentam marcadas as rimas finais. $\mathrm{O}$ emprego das rimas finais pode ser explicado pelo fato de tais poemas geralmente serem apresentados oralmente ao público. Para memorizá-los satisfatoriamente, a rima final desemprenhava uma importante função de auxílio. Além disso, a rima dá certo toque de leveza a um poema longo de cunho histórico.

\author{
Nicolau Engelmann \\ ( $\star 01.11 .1845$ Dois Irmãos - † 26.05.1920 Igrejinha) \\ GEDICHT ZUM PARAGUAY-KRIEG
}

Cheguei aos vinte anos (lá vai muito tempo), pensndo em gozar a vida... Então me levaram para o Paraguai. Tão fácil tal não teria sido se eu quisesse enganar o Brasil mas eu não tinha uma ideia tão vil, e estava disposto a dar minha vida. Só às vezes ficava lamentando perder meus jovens anos; foi quando via que uns heróis, se bem que não viam inimigos ainda, já se escafediam, abandonando a tropa e o posto,

\footnotetext{
9 Os pais de Nicolau Engelmann: Heinrich Engelmann (nasceu no dia 28.11.1803 em Argenthal, na Alemanha, e morreu no dia 14.08.1874, em Dois Irmãos, no Brasil) e Catharina Clo $\beta$ (nasceu no dia 03.10.1810, em Eckersweiler, Sachsen-Coburg, na Alemanha. Sobre sua morte não se tem informações).
} 
deixando pra nós o trabalho e o desgosto. ${ }^{10}$

No próximo recorte a ser analisado, dois aspectos merecem nossa atenção. Primeiro, os elementos linguísticos: são usados os termos "Stanze" e "Campamento". A palavra "Stanze" está empregada em dialeto, uma germanização da palavra "Estância" (também "Fazenda"). Engelmann usa outro termo, que, porém, não tem o mesmo sentido da palavra estância, vistas as palavras no seu sentido atual. Engelmann emprega a palavra "Campamento", derivada claramente do português "Acampamento" (Alemão: Lager). Cabe mencionar que a palavra estância também pode significar lugar de pouso, de parada depois de longa cavalgada ou caminhada. Nesse sentido, estância pode ser lida como "lugar onde se acampa". Engelmann também emprega a palavra portugesa "Capitao" seguida das iniciais do nome do mesmo.

A partir do emprego de datas pode-se ler uma clara preocupação dos autores com dados históricos. Engelmann usa uma data para marcar a chegada no acampamento, no dia 14 de julho de 1865: "14. Juli 1865 ins Campamento gekommen/ Sind viele von den Helden schon abgeschwommen".

Mas ficamos firmes - embora pensando tenhamos: "Que pena nós sermos soldados!"

Em quinze de julho de sessenta e cinto Recolhemos ao acampamento co'afinco. E $\log$ o F. D., o senhor capitão, Aos berros nos aplicou um sermão ${ }^{11}$

10 “Als erst mein zwanzigstes Jahr angefangen, Und ich glaubte, nun gibts viel Pläsier, Da ward ich zum Paraguaykriege geführt. Ich wäre wohl nimmer so leicht zu kriegen, Wenn ich nur wollte Brasilien betrügen, Aber dies war mir nicht in den Sinn gegeben, Gern setzte ich ein mein bischen Leben, Doch ich dachte oft und es tat mir leid: Schade, zu verlieren, die goldene Zeit. Auch dieses hätt' ich im Kriege vergessen, Wenn nicht so manche sich durchgefressen. Bald waren viele vom Posten fort, Und endlich blieben wir stehen dort."

11 "Da dachte ich schon in meinem Sinn:

$\mathrm{O}$ weh, dass Soldat ich geworden bin, So ist es dann immer weiter gegangen, Wie eben die Sache hat angefangen. 14. Juli 1865 ins Campamento gekommen, Sind viele von den Helden schon abgeschwommen. Da fing Capitao F. D. zu schreien an," 
No recorte seguinte, podem ser observadas mais indicações de tempo em ambos os autores. Também referências a locais são dadas, como por exemplo: Carioca, Passo da Areia, Santa Maria, São Borja. Mais um fator que marca a importância dada a referências históricas nos poemas. Através da leitura do poema, o leitor de hoje pode acompanhar a caminhada dos soldados rumo à guerra.

\author{
Em catorze de outubro, nós embarcamos \\ no "Carioca" e no outro dia chegamos, \\ a Rio Pardo. Ali, no quartel \\ nos receberam com farto farnel: \\ havia café e açúcar e pão - \\ um tratamento sem qualquer senão! \\ Também na chegada a Santa Maria, \\ ninguém podia queixar-se do dia, \\ porque as meninas daquela cidade \\ jogaram flores à nossa entrada. \\ E quando, garbosamente montados, \\ partimos, mais flores nos foram jogadas. \\ Com foguetório e banda, a gente, \\ tirando faíscas do calçamento, \\ partiu, e após jornada cheia \\ acampamos no Passo da Areia \\ por meses. Ali a nossa vida \\ era exercícios e ordem unida, \\ mas o que aprendemos não fez satisfeito \\ o comandante Rocha, um mau sujeito. \\ Afinal no dia seis do mês fevereiro \\ chegou a ordem: Marchar pra fronteira! \\ A oito de março, chegada em São Borja, \\ e já tremiam muitos da corja ${ }^{12}$
}

\footnotetext{
12 “Am 14. Oktober am Carioca embarkiert, Tags darauf in Rio Pardo einquartiert. Dort litten wir noch keine Not, Denn Kaffee gab's, auch Zucker und Brot.

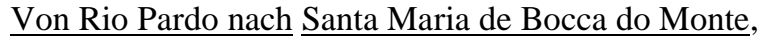
Man auch hier nicht weiter klagen konnte, Da dann bei Einkehr in das Städtchen Mit Blumen uns empfingen die Mädchen. Sie bestreuten auch mit Blumen die Strassen, Als wir wackern Soldaten zu Pferde sassen. Mit Musik und Raketengeknatter ging's munter Die holprige Strasse des Städchens hinunter. Am Passo de Areia kampierten wir monatelang, Und mit uns spielte Rocha, unser Kommandant. 6. Februar '66 begann bei ihm der Spleen, Als Ordre kam: Auf, nach der Grenze hin; Ankunft in São Borja am 8. März, Da sank so vielen in die Hosen das Herz."
} 
Além disso, cabe ressaltar aqui o registro da situação de fome em que viveram os soldados nesta guerra. Em outra passagem, o tema da fome e necessidade vividas pelos soldados é descrito da seguinte maneira:

O pouco gado foi devorado com pele e pêlo.

Até mesmo os cães viviam grande perigo.

Os burros da artilharia foram abatidos,

E deles os argentinos fizeram linguiça.

$\underline{\text { Vivíamos dia e noite de palmito }}^{13}$

Sabe-se hoje que a Guerra do Paraguai, assim geralmente são todas as guerras, marca um momento histórico negativo na América do Sul, especialmente porque o número de mortos foi enorme em ambas as partes - do lado da Aliança e do Paraguai - e também pelos cenários de mortes que se sucederam, como se lê no trecho a seguir:

De lá seguiu-se para a Lomba Valentin

E de novo para o Gran-Chaco,

Lá é que o plano foi colocado em prática.

Para acabar de vez com o inimigo, $\mathrm{O}$ plano foi visto como o mais correto. ${ }^{14}$

Na passagem a seguir é interessante observar a confusão no registro de nomes a partir da fixação oral feita por Engelmann, pois o nome do navio brasileiro "Cuiabá" (a capital do estado de Mato Grosso) passa a "Goiaba" (alemão: Guave). Além disso, o autor menciona no poema a dificuldade que os soldados passam depois do regresso a Porto Alegre, especialmente no que se refere à alimentação. Novamente eles passam fome, agora no Brasil:

No dia 26 de abril de 70, sábado de aleluia

Fomos embarcados no cargueiro Goiaba

Viajamos até o dia 24 de abril,

Em Rio Grande o cargueiro atracou. ${ }^{15}$

13 "Das wenig Vieh ward gefressen mit Haut und mit Haar.

Selbst die Hunde schon lebten in grosser Gefahr.

Der Artillerie (?) ihre Esel (?) wurden auch geschlacht't,

Davon die Argentiner haben Wurst gemacht.

Am Palmenherz lagen wir Tag und Nacht,"

14 "Von da ging's weiter nach Lommas alentinas

Und wieder darauf nach Gran-Chaco hin.

Dort wurde der Plan erst recht genommen,

Um richtig dem Feind in den Rücken zu kommen.

Gleich wurde der Plan für richtig befunden,"

15 “Am 26. April '70, Sabbado de Halleluja,

Schifften wir uns ein auf dem Dampfer Goiaba. 


\title{
E sobre os dias em Porto Alegre:
}

De fome o nosso estômago roncava.

Lá tínhamos, dia a dia, somente

Cinco feijões Xarque ruim como refeição. ${ }^{16}$

Ao final, destacam-se a importância de sua participação no lado brasileiro como imigrante alemão, os sentimentos de camaradagem, a honra dos que caíram na guerra e a alegria por poder voltar para casa, para junto da família.

\author{
Agora, ao lado de nossos pais, \\ passearemos por nossa cidade, \\ e, salvadores nós e heróis, \\ seremos saudados de todos os lados. \\ Nós conquistamos honra e glória, \\ porque Deus nos concedeu a vitória. \\ Pois cantem, gente de nossa terra, \\ em alegria e por gratidão: \\ "Deus, foi visível no horror da guerra \\ a Tua graça e Tua proteção!" \\ De fome, peste e de morte, \\ que nos cercavam, nos salvou \\ o nosso Deus grande e forte! \\ De volta à Pátria nos levou! \\ Nós vimos, bem a nosso lado, \\ tantos irmãos caídos, \\ Sendo também ameaçados \\ De sermos atingidos. \\ Cercados de destruição \\ e de fatais perigos, \\ Não nos valia a atenção, \\ nem o cuidar consigo... \\ eram da guerra e seu poder \\ todas as horas preenchidas, \\ e cada qual podia ser \\ o fim da nossa vida! ${ }^{17}$
}

Wir fuhren bis zum 24. April, In Rio Grande hielt der Dampfer still."

16 "Vor Hunger hat uns der Magen gekracht.

Dort gab es nur, Tag ein, Tag aus, Fünf Bohnen und schlechtes Xarque als Tagesschmaus."

17 "Jetzt kommen wir Retter mit Gesang,

Um Ruhm und Ehre zu bringen,

Ihr alle sollt mit lautem Dank

Dann mit uns Rettern singen.

Gott war bei uns in aller Not, Wir sahen ueberall den Tod,

Den Untergang uns drohen!

Nun wütet deiner Seuchen Heer Durch unser Vaterland nicht mehr, Sie sind von dir entflohen. 


\section{Conclusão}

Vimos aqui um poema que tem como tema a Guerra do Paraguai. Trata-se de um veterano de guerra que relata a sua participação em língua alemã, sua língua materna. Certamente Nicolau Engelmann falava a variante dialetal Hunsrückisch, o que justifica a presença de alguns termos na variante. O poema foi publicado em um almanaque em língua alemã no Brasil e aparentemente o objetivo da publicação estava em registrar a participação dos imigrantes alemães na guerra. Pode-se observar isso na "convocação" que Engelmann faz a seus camaradas para que escrevam e publiquem suas experiências.

Importante é destacar o emprego do Knittelvers no poema, o que pode ser visto como uma marca. Podemos nos perguntar por que Engelmann opta pela forma lírica em detrimento da prosa. Além disso, deveríamos nos perguntar se é natural que ele publique seu poema em língua alemã no Brasil. A possibilidade de publicação tem uma função importante neste caso? Quem deve ler este poema? O poema de Engelmann foi publicado postumamente, em 1921.

Vitor Volker Gans (2004, p. 335) traduziu o poema de Nicolau Engelmann para o português. Na passagem a seguir, ele relata sobre a sua tradução e como a termina:

\footnotetext{
$\mathrm{Na}$ transposição para o português, procurei manter o espírito e o tom do original, conservando inclusive (se bem que nem sempre no lugar preciso em que se encontram) as formulações ingênuas, as quebras de métrica, a introdução de rimas diferentes. Queremos chamar a atenção do leitor para a parte final do poema, em que o autor de alguma maneira se deixa arrebatar, e em que a sua linguage se torna mais fluente, rica e musical - quase chegando a atingir o nível da poesia autêntica. Espero que a tradução tenha conseguido preservar esta riqueza. (apud ENGELMANN, 2004, p. 335)
}

O poema tem no eu-lírico a figura do autor e desta forma o leitor pode acompanhar o relato do soldado. Em algumas passagens, por outro lado, pode se perceber a forma Nós.

Wir sahen hier, wir sahen dort,

So viele Brüder sterben,

Und allenthalben Waren wir

Umfangen vom Verderben.

Dort war kein Schonen,

Stündlich war

Und furchtbar nahe die Gefahr,

Auch alle Kunst vergebens.

Nichts trieb des Kriegers macht zurück

Und uns schien jeder Augenblick

Der letzte unseres Lebens." 
Isto significa que um grupo é representado no trabalho literário em torno da Guerra do Paraguai e o objetivo é registrar a experiência.

\section{Referências}

BADE, Klaus J. Massenwanderung und Arbeitsmarkt im deutschen Nordosten von 1880 bis zum Ersten Weltkrieg: Überseeische Auswanderung, interne Abwanderung und kontinentale Zuwanderung. In: Archiv für Sozialgeschichte 20, 1980, S. 265 - 323.

BECKER, Klaus. Alemães e descendentes do Rio Grande do Sul na Guerra do Paraguai. Canoas: Editora Hilgert, 1968.

BENTO, Cláudio Moreira. Estrangeiros e descendentes na história militar do Rio Grande do Sul-1635 a 1870. Porto Alegre: A Nação; Instituto Estadual do Livro, 1976.

DORATIOTO, Francisco F. Monteoliva. Maldita guerra: nova história da Guerra do Paraguai. São Paulo: Companhia das Letras, 2002.

ENGELMANN, Erni G. A Saga dos Alemães - do Hunsrück para Santa Maria do Mundo Novo. s.1. s.e. 2004, p. 334-341.

ENGELMANN, Nicolau. "Erinnerungen an den Paraguay-Krieg.” In: Kalender für die Deutschen in Brasilien. São Leopoldo: Ed. Rotermund, 1921. p. 193-201.

FLORES, Hilda A. Hübner. Alemães na Guerra dos Farrapos. Porto Alegre: EDIPUCRS, 1995.

HUNSCHE, Carlos H. O biênio 1824/1825 da imigração alemã no Rio Grande do Sul (Província de São Pedro). Porto Alegre: A Nação; IEL, 1975.

KREUTZ, Lúcio. O professor paroquial - magistério e imigração alemã. Porto Alegre: UFRGS; Caxias do Sul: EDUCS; Florianópolis: UFSC, 1991.

MÖNCKMEIER, Wilhelm. Die deutsche überseeische Auswanderung. Ein Beitrag zur deutschen Wanderungsgeschichte. Jena: Verlag von Gustav Fischer, 1912.

ROCHE, Jean. A colonização alemã e o Rio Grande do Sul - I e II. Trad. Emery Ruas. Porto Alegre: Globo, 1969.

ROTHMANN, Kurt. Kleine Geschichte der deutschen Literatur. Stuttgart: Philipp Reclam Verlag, 1992.

TORAL, André. Adeus, chamigo brasileiro.Uma história da Guerra do Paraguai. São Paulo: Companhia das Letras, 1999. 
STROHTMANN Direktor. "Der Paraguay-Krieg. Anlässlich der fünfzigjährigen Wiederkehr des Beginns in geschichtlichen Umrissen bearbeitet." In: Kalender für die Deutschen in Brasilien. São Leopoldo: Ed. Rotermund, 1915, p. 38-46.

"Vom Feldzug gegen Paraguay. Einem Kriegsfreiwilligen nacherzählt." In: Kalender für die Deutschen in Brasilien. São Leopoldo: Ed. Rotermund, 1908, p. 62-84.

WINIGER, Josef. "Die Triple-Allianz gegen Paraguay. Zur Eröffnung des Paraguaykrieges vor 50 Jahren." In: Kalender für die Deutschen in Brasilien. São Leopoldo: Ed. Rotermund, 1916, p. 118-121.

“Zum 50-jährigen Jubiläum des Paraguayer Krieges 1865.” In: Kalender für die Deutschen in Brasilien. São Leopoldo: Ed. Rotermund, 1915, p. 519-520.

\section{Anexo}

I - Figura 1 - In: Kalender für die Deutschen in Brasilien, 1921, p. 201.

\section{Riebe Friegskameraden!}

Wir alle baben für bie (Ebre des $\mathfrak{B}$ aterlandes gekämpft. (Euch allem, bie ibr nod) am seben feto, fei beute mein berslictier (Brup gebracht. 5 bon viele unirer $\varsigma_{3} a$ meraden jind interbalb der 42 Jabre in die grobe 2lrmee abgerufen. Bald pon Diejem, bald pon jenem las idi) in Der "Deutichen Polt" die Todesmachricht. So wird auch bald die Reibe an uns kom=

men. Dann foll ntcht vergefien werden, Daß̉ Dte Deutiche Batterie etren mejentlichen Tell zum Siege im Waraguar)= Sriege betgetragen bat. Darum bieß es auch tmmer: Viva Bateria dos Allemães! Drum, alle Frtegskameraden, lebt mob!! 